\title{
Improving Self-Efficacy in Musical Performance Using Socratic Dialogue
}

\author{
Imanuel Ezra ${ }^{1}$ \\ Flinders University, Australia \\ ezra.sutanto@hotmail.com
}

\begin{abstract}
This research try to investigate the effect of promoting self-efficacy to musical performance in a student, which had been done by explaining the student about the concept of self-efficacy, and a series of Socratic dialogue. This educational intervention was done to a junior high school student (X). Pre and post intervention measuring test were done using Pintrich and Groot's Motivated Strategies for Learning Questionnaire (1990) that had been adapted to suit the context of music education. This study found that improving self-efficacy level in a student using Socratic Dialogue does have positive effect on musical performance and practice
\end{abstract}

\section{KEYWORDS Self-efficacy, socratic dialogue, MSLQ}

CITATION Ezra, I. (2019). Improving self-efficacy in musical performance using socratic dialogue. Cognicia, 7, (2), 153-159.

Self-efficacy is a concept suggested by Albert Bandura that is used to explain "a judgment of one's ability to perform a task within a specific domain" and attain designated goals (Bandura, 1997, in Bruning et al., 2004, p.112). Self-efficacy has several elements that are essentials to differentiate it from another similar yet different belief about self, including self-esteem, self-confidence or constructs such as locus of control and outcome expectancies. First self-efficacy is concerned only to a certain domain (Bandura, 1997). Being distinct to a domain, having a high self-efficacy in one domain does not guarantee a high self-efficacy in another domain (although at times, a high level of self-efficacy in a domain may translate to self-efficacy in the related domain, (Zimmerman, 2000).

Second element of self-efficacy is it deals solely to perception of one's capability (Bandura, 2006). Hence, it deals with whether the subject can attain designated goals or not, instead of whether the subject will attain it or not. Self-efficacy might determine one's intention or not, but both constructs are separable (Bandura, 2006).

The third element is perception of efficacy only considers one's own capability to successfully do a task, in other words, one's own mastery (Zimmerman, 2000). Someone's level of self-efficacy does not depend on how well one's will do compared with others (Zimmerman, 2000), although, Bandura noted that social comparison does influence how people judge their ability (Bandura, 1993).

Last element of self-efficacy is it speaks about the future. When students assess their own self-efficacy, they are predicting before they perform an activity, how well they will function in the future related to the activity they are going to perform 
(Zimmerman, 2000). Because the assessment is done before the execution, it affects the academic motivation (Zimmerman, 2000) and performance (Bandura, 1993) causally.

Given how one characteristic of self-efficacy is its specificity (Bandura, 2006), a research investigating self-efficacy should be done domain by domain, making virtually countless possibilities how self-efficacy can affect performance. One domain that only recently has been researched regarding its link to self-efficacy is music (McPherson \& McCormick, 1999 in McPherson \& McCormick, 2003).

Ever since the research to find a link between self-efficacy and music learning conducted, the results have always been consistent that self-efficacy holds an important role within music learning. Even then music has several constructs within it which significantly affected by self-efficacy, and different skill base for a sub-area of a domain might be required (1996). This paper will explain the effect self-efficacy based on its significance within two sub area of music-learning, namely musical performance and practice.

Self-efficacy improving the students' musical practice by improving the quality of the deliberate practice done by the student, and also promoting the sustainability of the practice itself (Nielsen, 2004; McCormick \& McPherson, 2003;2006; Ritchie and Williamon, 2007). Students who have better self-efficacy to learn music apply more cognitive, metacognitive, and resource management strategies (Pintrich \& Groot, 1999; Nielsen, 2004). Pintrich (1999) particularly noted that students more likely to use three cognitive strategies (elaboration, rehearsal, and organisational strategies) and three metacognitive strategies (planning, monitoring, and regulating) if they feel more efficacious about their ability.

The sustainability of the practice itself is also improved, because self-efficacy fosters the effort given to the practice (Zimmerman, 2000), perseverance when encountering difficulties (Pajares, 1996 in McPherson and McCormick, 2000), and grit (Miksza and Tan, 2015) which translates into "perseverance and passion for long term goals" (Duckworth et al., 2007, p. 1087) and self-regulated learning (McPherson and McCormick, 2006). McPherson and McCormick (2006) particularly note the importance of those aforementioned effect self-efficacy gives, as learning to play an instrument is a difficult and complicated task, and demands high level of physical, mental, and emotional effort. Being self-regulated also highly important, as in current setting of music education, learners often should do the practice self-scheduled, and "often left to their own devices to choose for themselves how and when they will complete their practice". ( p.335). This is not to mention that self-regulation also predicts effort expenditure, and persistence (Zimmerman, Bandura, \& Martinez-Pons, 1992 in Miksza and Tan, 2015)

To boost X's self-efficacy, intervention will be done using cognitive behavioural therapy in the form of socratic dialogue. In this part of the paper theoretical justification will be given on how socratic dialogue is an effective method to be used to boost self-efficacy.

Socratic dialogue is described as mutual discovery by questions and answers to find out automatic thoughts and assumptions, whose logic and evidence behind it will be analysed together (Leahy, 2001 in Freeman, 2005). It is a combination of interpreting someone's idea based on the intentions, motivations, and hidden conflicts behind it 
and paraphrasing statements (Freeman, 2005). It takes the best of both world, in that it is still guiding someone to new, helpful insights, but giving the subject the freedom to find it by himself, without the feeling of forcing new value to the subject (Freeman, 2005). According to Freeman (2005), this will lead to insight, integration, and change of both behaviour and thought. Moreover, because of its voluntary nature, the insight gain after socratic dialogue process can be accepted by the student (Claiborn and Dixon, 1992 in Kazantzis et al., 2014).

In relation to self-efficacy, socratic dialogue has been used to enhance learning (Zachry, 1985 and Legrenzi, 1971 in Kazantzis et al., 2014). Socratic also showed to be able to develop flexibility regarding someone's assumption to aid emotional distress and reduced functioning (DiGiuseppe, 1991; Friedberg \& McClure, 2002; Overholser, 1993 in Kazantzis et al., 2014), two things that often present in someone with low selfefficacy (Solberg et al., 1997; Bandura, 1993).

Socratic dialogue in this research will be used to give $x$ (participant in the case study intervention at the focus of this paper) insight that can help $\mathrm{x}$ improve his selfefficacy level. One example is using it to give insight about Carol Dweck's growth mindset. A growth mindset can be described as a mindset that views intelligence and ability as developable instead of fixed, and see challenges, failure and difficulties as opportunities to improve through practice and effort (Cassidy, 2015). This is found to give grit and academic resiliency to students, which has high correlation with high level of self-efficacy in students (Hamill, 2003 in Cassidy, 2015).

The change of level of X's self-efficacy will be measured using two methods, qualitative and quantitative. Qualitatively, it will be measured using short structured interview and observation. $X$ will be given a series of reflecting question regarding how does he feel, what does he think about his course, and etc. X's body language will be also observed. Since self-efficacy influences behaviour, its level will also be reflected in someone's conscious or unconscious behaviour (Zimmerman, 2000). Given that low level of self-efficacy correlate with distress and doubt emotion (DiGiuseppe, 1991; Friedberg \& McClure, 2002; Overholser, 1993 in Kazantzis et al., 2014), this paper will observe the change of expression that is associated with distress and doubt, including stutter, frustration, frown, or whether there is smile, laugh, sign of enjoying the music, or not.

Quantitative measurement will be done using an adapted version of Pintrich and Groot's Motivated Strategies for Learning Questionnaire (1990). This questionnaire consists of a set of statement and 7 point scale Likert scale (from $1=$ not relatable at all, to $7=$ very relatable for me) to measure how relatable each item is to the subject. The researcher has adapted the original 56-items questionnaire into 35 items questionnaire whose setting has been changed to music education. Among those 35 items, 9 items specifically measuring self-efficacy, whilst the others measuring construct that are related to self-efficacy, including intrinsic value, cognitive strategy used, and selfregulation (Pintrich and Groot, 1990). Although this paper is mainly about self-efficacy, these constructs were kept in the questionnaire to gain further insight how self-efficacy affected $X^{\prime}$ 's performance in this research.

\section{METHOD}


Therefore, justified by the abundance of previous literature that support the notion, it is believed that raising the student's self-efficacy through socratic dialogue will result in improvement over his musical performance.

\section{CASE STUDY DETAILS}

$X$ is a 14 years old Indonesian student that has been enrolled in Adelaide International school for two years. $X$ did not have formal background in music, but try to learn it by modelling videos in social media. The instrument he has learnt including bass guitar, acoustic guitar, and piano, with the latter instrument being his weakest.

The intervention will be done three times, which consist of teaching $X$ a scale for forty five minutes, and Socratic dialogue for thirty minutes. There is a gap of five days between each intervention. Two days before the first intervention, $X$ and $X$ 's parents were briefed about the intervention that will be done, and in the same day they fill up the informed consent, and X fill up the pre-test questionnaire (which is an adapted version of Pintrich and Groot's Motivated Strategies for Learning Questionnaire (Pintrich and Groot, 1990). Two days after the last intervention, they were debriefed once more, and a post-test intervention using the same scale was given.

\section{RESULTS}

Quantitatively, subject showed good result about his self-efficacy. Out of 63 possible score for self-efficacy, he answered 53. Almost every statement in self-efficacy dimension was answered with 6 (relatable) or 7 (very relatable).

This is consistent with several psychologist findings that self-efficacy often correlate with years of experience in the early until mid-phase of learning (Klassen and Chiu, 2010). As $X$ has not learnt piano formally before, it is understood that this lowered X's self-efficacy, albeit the good overall score $X$ got.

However qualitatively there are some sign that were inconsistent with $X$ general high score. $X$ often showed doubt when being asked to play a part and frustrated after a few fail. Some of the body languages and behaviour that can be interpreted as doubt is being reluctant to try, unclear or stutter when answering question whether he can do it or not, and repeatedly self-asked whether X can do it or not. Body languages and behaviour that might be sign of frustration were shaking head after fail to play a part, repeatedly asking for break (which $\mathrm{X}$ claimed because he was thirsty or needed to go to the toilet), and asked to postpone a lesson material. In interview, even though some of the sign still present, generally $\mathrm{X}$ answered the question in more confident manner, which was in-line with his answer about his self-efficacy.

Performance-wise, $X$ showed that $X$ was a novice in piano, that although has shown a proof that $X$ indeed had tried to learn piano in the past (from the web), but when being asked to play $\mathrm{X}$ committed elementary mistakes that were characteristic of people who did not learn piano formally.

\section{INTERVENTION}

Educational intervention was done in two part: teaching and modelling $\mathrm{X}$ how to play a song in piano, and socratic dialogue regarding self-efficacy, growth mindset, and attributional style afterward. 
During the first part (teaching piano), there are some cognitive and metacognitive strategies that researcher apply into the lesson, whether it was planned or to aid the learning whenever $X$ was troubled. A sample of cognitive strategy applied was to ask $X$ repeat the harder part of the song in slower tempo, asked him to play right hand or left hand first to reduce cognitive load in learning new part, and provide a real-time example for $X$ to model to. Metacognitive strategy that was implemented in the lesson was asking $X$ to monitor $X^{\prime}$ s practice and set a goal or objective before practice.

Socratic dialogue that was done after that was used to give $X^{\prime}$ 's insight about psychology concepts that will help improve $X^{\prime}$ s level of self-efficacy, which in this case were growth mindset and attributional style. The dialogue usually consisted of discussing, with lots of reflective questions and answers in the middle, with conclusion being given after each correct point or idea about psychological concept was made. For example, in the second intervention we were talking about inspiring figure in sports that $\mathrm{X}$ admire (for example, $\mathrm{R}$ ). $\mathrm{X}$ believed that $\mathrm{R}$ could be successful because $\mathrm{R}$ was talented and born with that talent. To challenge that idea (and give $\mathrm{X}$ insight about growth mindset), a question to imagine if $\mathrm{R}$ did not have the talent yet keep practicing were asked. This made $X$ thought that practice, too, was important. Then a concluding statement that practice is important were given. This would be done until all point that wanted to be given were learned in that day (usually in 30 minutes, all points were delivered).

After three days of intervention, performance-wise $X$ showed good improvement in X's piano skills, able to play a simple song independently without a pause in the middle of the song. Qualitatively, X looked more confident, able to enjoy X's own playing ( $X$ hummed the song $X$ played, and sometimes tapped X's foot or nodded X's head in conjunction with the beat of the song), and achieved automaticity for the simple part of the song, something that can be achieved with constant repetition and practice (Bruning et al., 2003).

This result is in-line with $X^{\prime}$ s quantitative result, in which $X$ got 60 points, a 7 points improvement from $X^{\prime}$ 's pre-test. Moreover, every self-efficacy related statement is either relatable or strongly relatable now, including the ones $\mathrm{X}$ answered not relatable before.

\section{DISCUSSION}

The hypotheses this research first made that improving self-efficacy through socratic dialogue would improve musical performance is well-supported with the result of the test, both qualitatively and quantitatively. This result also consistent with literature and research that has been done before regarding self-efficacy and musical learning.

This result supports the findings in previous literature, that high level of selfefficacy is beneficial to musical learning (McPherson and McCormick, 2003). The benefits also similar to what have been found before, in that self-efficacy both increase the quality of the formal practice done by the student and sustainability of the practice.

$X^{\prime}$ 's quality of practice improves because as heightening $X^{\prime}$ 's self-efficacy at the same time heightening $X^{\prime}$ 's self-efficacy to apply various cognitive and metacognitive 
strategy in X's musical practice, and be more self-regulated in practicing (Pintrich and Groot, 1999; Nielsen, 2004). X in particular showed a more sophisticated way of training, having a goal to achieve, and applying cognitive strategies in face of difficulties. Quantitatively, X also saw an improvement of 11 points in self-regulated learning strategies dimension in Motivated of Learning Strategies Questionnaire (1990)

$X^{\prime}$ s practice sustainability also improved greatly. This is due to the fact that increasing X's self-efficacy also means increasing X's resiliency, perseverance, and persistence to train harder and not giving up (Miksza and Tan, 2015).

This increased resiliency is apparent in two ways. Quantitatively, $X$ scored higher in the post-test self-regulation dimension by 8 points, and qualitatively, $X$ ensured that $X$ had practiced before every lesson, and $X$ showed more resilience, less tendency to be frustrated, and increased curiosity instead of giving up when facing difficult part of the song.

Both changing fixed mindset into growth mindset and maladaptive attributional style to the adaptive one has shown to be beneficial to $X$. This change provide motivation for $X$ to achieve more, and giving $X$ the resiliency needed to achieve it. By changing $\mathrm{X}$ attributional style, $\mathrm{X}$ learns what are things that are controllable and not, hence can strive to maximise what $X$ can control to achieve better things (which before were thought as 'given'), in this case, music ability.

\section{CONCLUSION}

Improving self-efficacy level in a student does have positive effect on performance and practice. This is made possible because self-efficacy both increase the quality and sustainability of the practice, something that is deemed essential in learning music instrument (McPherson and McCormick, 2003).

Socratic dialogue has also been shown to be effective method in increasing selfefficacy. By being non-confrontative, the insight that is gained from the dialogue can be more readily accepted by the supervisee (Freeman, 2005), hence able to change mindset that was deeply rooted in someone into the more adaptive one, in this case, fixed mindset of intelligence into growth mindset (Cassidy, 2015).

Improvement in future research can be done by eliminating possible confounding factor (such as the quality of the teaching provided), and increasing the sample of the study so the result can be generalised to more people.

The relation of which self-efficacy can improve performance should be investigated more as well. It is being understood that self-efficacy is related to numerous self-beliefs and similar construct that are beneficial to performance, such as self-regulated learning, cognitive strategy used (Pintrich and Groot, 1990), self-esteem (Zimmerman, 2000), and expectancies outcomes (Bandura, 1996). Further research into this relation can provide better insight on how self-efficacy affect performance, directly or indirectly (McPherson and McCormick, 2003 and 2006).

\section{REFERENCE}

Bandura, A. (1993). Perceived self-efficacy in cognitive development and functioning. Educational psychologist, 28(2), 117-148.

Bandura, A., \& Wessels, S. (1997). Self-efficacy (pp. 4-6). W.H. Freeman \& Company. 


\section{Cognicia}

http://ejournal.umm.ac.id/index.php/cognicia

Bandura, A. (2006). Guide for constructing self-efficacy scales. Self-efficacy beliefs of adolescents, 5(1), 307-337.

Bruning, R. H., Schraw, G. J., Norby, M. M., \& Ronning, R. R. (2003). Cognitive psychology and instruction. Prentice-Hall, Inc., One Lake Street, Upper Saddle River, NJ 07458.

Cassidy, S. (2015). Resilience building in students: the role of academic self-efficacy. Frontiers in psychology, 6, 1781.

Duckworth, A. L., Peterson, C., Matthews, M. D., \& Kelly, D. R. (2007). Grit: perseverance and passion for long-term goals. Journal of personality and social psychology, 92(6), 1087.

Freeman, A. (2005). Socratic dialogue. In Encyclopedia of cognitive behavior therapy (pp. 380-384). Springer, Boston, MA.

Judge, T. A., \& Bono, J. E. (2001). Relationship of core self-evaluations traits-self-esteem, generalized self-efficacy, locus of control, and emotional stability-with job satisfaction and job performance: A meta-analysis. Journal of applied Psychology, 86(1), 80.

Kazantzis, N., Fairburn, C. G., Padesky, C. A., Reinecke, M., \& Teesson, M. (2014). Unresolved issues regarding the research and practice of cognitive behavior therapy: The case of guided discovery using Socratic questioning. Behaviour Change, 31(1), 1-17.

McPherson, G. E., \& McCormick, J. (1999). Motivational and self-regulated learning components of musical practice. Bulletin of the Council for Research in Music Education, 98-102.

McPherson, G. E., \& McCormick, J. (2000). The contribution of motivational factors to instrumental performance in a music examination. Research Studies in Music Education, 15(1), 31-39.

McCORMICK, J., \& McPHERSON, G. (2003). The role of self-efficacy in a musical performance examination: An exploratory structural equation analysis. Psychology of Music, 31(1), 37-51.

McPherson, G. E., \& McCormick, J. (2006). Self-efficacy and music performance. Psychology of music, 34(3), 322-336.

Miksza, P., \& Tan, L. (2015). Predicting collegiate wind players' practice efficiency, flow, and self-efficacy for self-regulation: An exploratory study of relationships between teachers' instruction and students' practicing. Journal of Research in Music Education, 63(2), 162-179.

Nielsen, S. G. (2004). Strategies and self-efficacy beliefs in instrumental and vocal individual practice: A study of students in higher music education. Psychology of Music, 32(4), 418431.

Pintrich, P. R., \& De Groot, E. V. (1990). Motivational and self-regulated learning components of classroom academic performance. Journal of educational psychology, 82(1), 33.

Ritchie, L., \& Williamon, A. (2011). Measuring distinct types of musical self-efficacy. Psychology of Music, 39(3), 328-344.

Ritchie, L., \& Williamon, A. (2007, November). Measuring self-efficacy in music. In Proceedings of the International Symposium on Performance Science (pp. 307-312).

Vyskočilová, J., \& Praško, J. (2012). Socratic dialogue and guided discovery in cognitive behavioral supervision. Activitas Nervosa Superior Rediviva, 54(1).

Zimmerman, B. J. (2000). Attaining self-regulation: A social cognitive perspective. In Handbook of self-regulation (pp. 13-39).

Zimmerman, B. J. (2000). Self-efficacy: An essential motive to learn. Contemporary educational psychology, 25(1), 82-91. 